\title{
Article Computational Assessment of Botrytis cinerea Lipase for
Biofuel Production
}

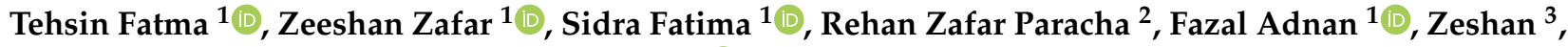 \\ Nasar Virk ${ }^{1,4}$ and Muhammad Faraz Bhatti ${ }^{1, *(D)}$
}

1 Atta-ur-Rahman School of Applied Biosciences (ASAB), National University of Sciences and Technology (NUST), Islamabad 44000, Pakistan; tehsinfatima55@gmail.com (T.F.); zeeshanzafar98@hotmail.com (Z.Z.); sidrafatima49032@yahoo.com (S.F.); adnanfazal@asab.nust.edu.pk (F.A.); nasarvirk@asab.nust.edu.pk (N.V.)

2 Research Center for Modeling and Simulation (RCMS), National University of Sciences and Technology (NUST), Islamabad 44000, Pakistan; rehan@rcms.nust.edu.pk

3 Institute of Environmental Sciences and Engineering (IESE), National University of Sciences and Technology (NUST), Islamabad 44000, Pakistan; zeshansheikh@iese.nust.edu.pk

4 EBS Business School, EBS Universität für Wirtschaft und Recht, Rheingaustrasse 1, 65375 Oestrich-Winkel, Germany

* Correspondence: mfbhatti@asab.nust.edu.pk

Citation: Fatma, T.; Zafar, Z.; Fatima, S.; Paracha, R.Z.; Adnan, F.; Zeshan; Virk, N.; Bhatti, M.F. Computational Assessment of Botrytis cinerea Lipase for Biofuel Production. Catalysts 2021 11, 1319.

https://doi.org/10.3390/catal11111319

Academic Editor: Gabriel Morales

Received: 20 September 2021

Accepted: 28 October 2021

Published: 30 October 2021

Publisher's Note: MDPI stays neutral with regard to jurisdictional claims in published maps and institutional affiliations.

Copyright: (c) 2021 by the authors. Licensee MDPI, Basel, Switzerland. This article is an open access article distributed under the terms and conditions of the Creative Commons Attribution (CC BY) license (https:// creativecommons.org/licenses/by/ $4.0 /)$.

\begin{abstract}
The demand for ecofriendly green catalysts for biofuel synthesis is greatly increasing with the effects of fossil fuel depletion. Fungal lipases are abundantly used as biocatalysts for the synthesis of biofuel. The use of Botrytis cinerea lipase is an excellent approach for the conversion of agroindustrial residues into biofuel. In this study, phylogenetic analyses were carried out and the physicochemical properties of $B$. cinerea lipase were assessed. Furthermore, the protein structure of $B$. cinerea lipase was predicted and refined. Putative energy-rich phytolipid compounds were explored as a substrate for the synthesis of biofuel, owing to B. cinerea lipase catalysis. Approximately 161 plantbased fatty acids were docked with $B$. cinerea lipase in order to evaluate their binding affinities and interactions. Among the docked fatty acids, the top ten triglycerides having the lowest number of binding affinities with $B$. cinerea lipase were selected, and their interactions were assessed. The top three triglycerides having the greatest number of hydrogen bonds and hydrophobic interactions were selected for simulations of $20 \mathrm{~ns}$. The docking and simulations revealed that docosahexaenoic acid, dicranin, and hexadeca-7,10,13-trienoic acid had stable bonding with the B. cinerea lipase. Therefore, $B$. cinerea lipase has the potential to be used for the transesterification of fatty acids into biofuels, whereas docosahexaenoic acid, dicranin, and hexadeca-7,10,13-trienoic acid can be used as substrates of $B$. cinerea lipase for biofuel synthesis.
\end{abstract}

Keywords: Botritis cinerea lipase; plant fatty acids; biofuels; molecular docking; molecular dynamics simulations; green catalysis

\section{Introduction}

Fossil fuels are unable to deal with the increasing demand for energy, as they are nonrenewable [1-3]. Biofuels are preferred over conventional fuels because of their nontoxic, biodegradable, and renewable natures. Moreover, biofuels offer lower impact in terms of global carbon footprints [3]. Biofuel synthesis is the best alternative for coping with fossil fuel consumption. According to a report, biofuel global production was increased by 10 billion liters in 2018, compared to 2017, to meet a record of 154 billion liters [4]. A twenty-five percent increase in biofuel production is forecasted by the year 2024, due to the better growth statuses of biofuel-producing countries, including Brazil, the United States, and, especially, China [5]. Among all the countries, Brazil has the prominent agricultural backbone to convert agroindustrial waste into renewable energy products [6]. Biobased residues, including fats and oils, are most frequently used for the synthesis of biofuels. 
These contain energy-rich and readily available triglycerides, having a reduced carbon source [7]. The demand for nonedible vegetable oils as a potential second-generation feedstock for biofuel production has significantly increased. Jatropha curcas, Sterculia feotida, and many other nonedible oil-producing plant feedstock is utilized for ecofriendly and sustainable biodiesel production, which is catalyzed by fungal lipases. [8].

Biological pretreatments using fungal fermentation processes are considered to be a highly efficient approach for the downstream production of biofuel, but the duration of incubation extends from weeks to months [9]. Hence, microbial enzymes are popular for catalyzing complex substrates into renewable fuels within hours, leading to maximum yields [10]. Different technical approaches, including thermochemical, physicochemical, and biological methods, are being used for the sustainable and successful treatment of biomass before conversion into biofuel using microbial enzymes [11,12]. Fungal lipases, such as Candida lipases, are widely used for biodiesel production $[4,13]$. The lipases of other fungi, including Aspergillus niger, Rhizopus oryzae, and Rhizomucor miehei are also well-known sources for commercial biodiesel production [13,14].

Lipases have the ability to catalyze triglycerides into diglycerides, monoglycerides, glycerol, and the free form of fatty acids. Lipases catalyze the released free sterols and fatty acids by acting as sterol esterases [15]. Lipases are popular in commercial industries, including in detergents, wastewater pretreatment, food processing, chemical synthesis, biofuel production, and the paper and textile industries [16,17]. Fungal lipases are classified based on the type of amino acid needed to form oxyanion holes, as in the GX, GGGX, and $Y$ classes, and are further categorized into five subclasses: two GX, two GGGX, and one $Y$ [18]. G indicates conserved glycine joined with C-terminal backbone neighbor X, being the hydrophobic residue of an oxyanion hole. The Y-class consists of Candida antarctica lipase A, such as in [19]. Fungal lipases have molecular masses ranging from $20 \mathrm{kDa}$ to $60 \mathrm{kDa}$, approximately, in various fungi species [20]. Lipases are promising catalysts for biofuel production because of their high specificity for the transesterification of fatty acids into methyl or ethyl esters at the industrial level [21].

B. cinerea is well-known for its enzymatic repertoire and for actively participating in various metabolic pathways, including the cAMP signaling pathways and MAPK cascades [22]. It is a most significant necrotrophic fungus, infamous for causing pathogenesis in more than 200 plant species because it secretes several effector proteins and cell-walldegrading enzymes, including lipases [23,24]. Lipase extracted from B. cinerea demonstrated significant similarity with lipases isolated from Candida rugosa and the Geotrichum species. However, $B$. cinerea lipase showed a higher protein similarity with filamentous fungi, including the Aspergillus species [23]. Hence, B. cinerea lipase can also be used as a potential biocatalyst.

Since the molecular characterization of B. cinerea lipase has not been reported yet, the current study assessed the various plant-derived fatty acids and triglyceride molecules as substrates of $B$. cinerea lipase in order to produce cost-effective biofuel. Therefore, an in silico molecular characterization of $B$. cinerea lipase was carried out. Plant-based fatty acids were used to perform molecular docking and molecular dynamics simulations in order to identify efficacious fatty acids for B. cinerea lipase to produce biofuel. This study provides novel insights into Botrytis cinerea lipases, and identifies the plant-derived fatty acids best suitable for biofuel production using B. cinerea.

\section{Results}

\subsection{Multiple Sequence Alignment and Phylogenetic Analysis of B. cinerea Lipase}

The physicochemical properties of $B$. cinerea lipase are represented in Table 1. Multiple sequence alignment revealed that lipases in Botrytis share higher identity within the genus. The active site, in the form of catalytic residues (G-X-S-X-G), is conserved in all fungal lipases. For the phylogenetic tree, multiple sequence alignment was used to generate a maximum likelihood tree on MEGAX software, as shown in Figure 1. The phylogenetic tree, based on the protein sequences of isolates, is represented in Figure 2. The tree was 
divided into subgroups. B. cinerea lipase showed a close relationship with Botrytis cinerea lipase, and forms a sister clade with the lipases of other Botrytis species, and with the lipases of many different fungal species. However, it showed a distant relationship with the lipases of Rutstroemia sp., Lepidopterella palustris, and Coleophoma crateriformis. The lipase from Vibrio coralliilyticus was an outgroup in the rooted phylogenetic tree.

Table 1. Physicochemical properties of B. cinerea lipase. Physicochemical properties, including amino acid residues, molecular weight, theoretical pI, positively and negatively charged residues, molecular formula, instability index, aliphatic index (\%), and GRAVY, are represented in the table.

\begin{tabular}{ccc}
\hline Sr. No & Physiochemical Properties of B. cinerea Lipase & Values \\
\hline 1 & Amino acid Residues & 557 \\
\hline 2 & Molecular weight (Da) & $59,090.04$ \\
\hline 3 & Theoretical pI & 4.93 \\
\hline 4 & Positively Charged Residue & 30 \\
\hline 5 & Negatively Charged Residue & 38 \\
\hline 6 & Total No. of Atoms & 8312 \\
\hline 7 & Molecular formula & $\mathrm{C}_{2703} \mathrm{H}_{4129} \mathrm{~N}_{675} \mathrm{O}_{797} \mathrm{~S}_{8}$ \\
\hline 8 & Instability index & 36.20 \\
\hline 9 & Aliphatic index (\%) & 92.21 \\
\hline 10 & GRAVY & 0.194 \\
\hline
\end{tabular}
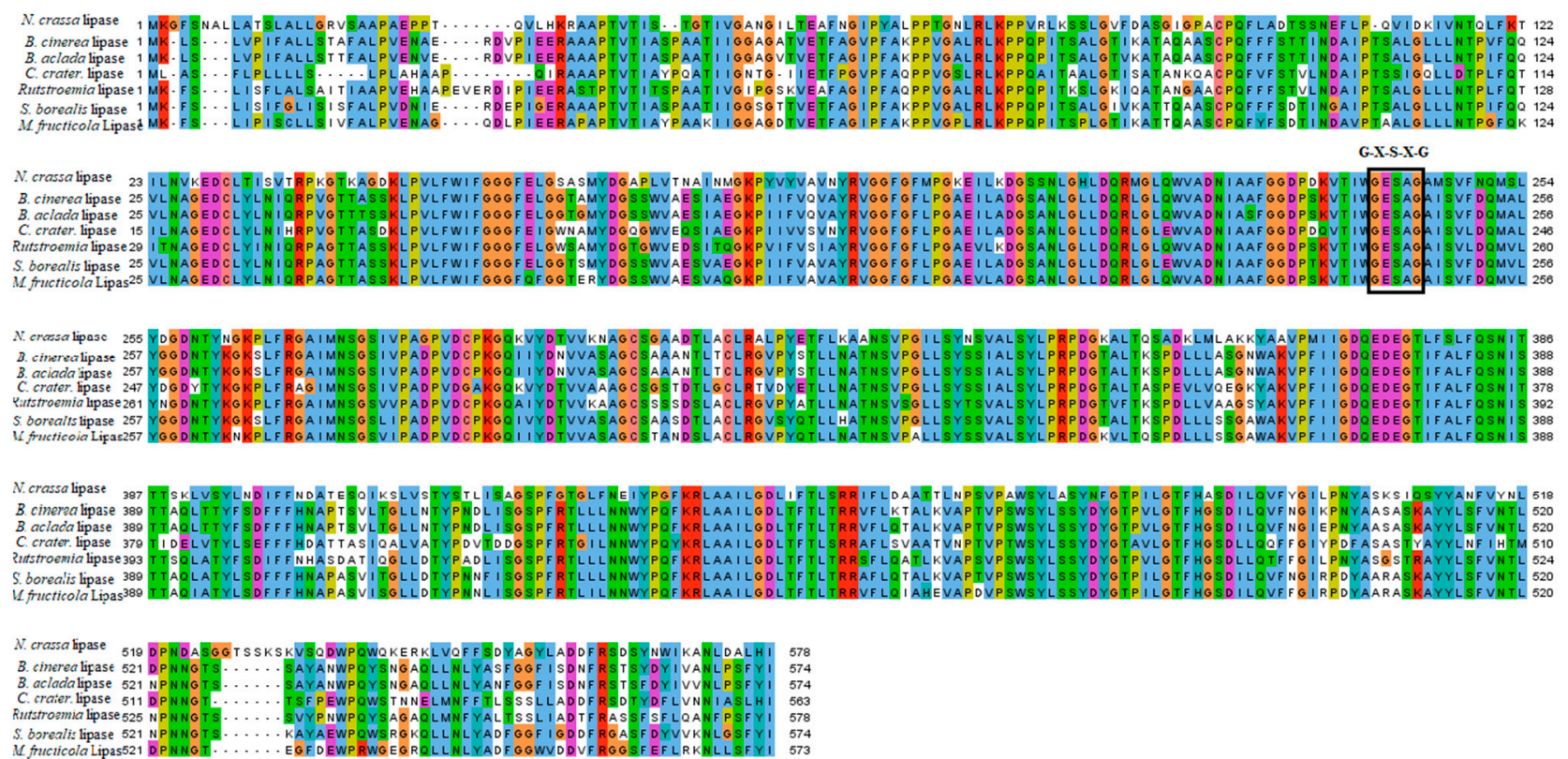

Figure 1. Multiple sequence alignment of Botrytis cinerea lipase. Multiple sequence alignment of Botrytis cinerea lipase. Conserved amino acids have been highlighted in colors. Catalytic triad (GXSXG) is shown in the box. 


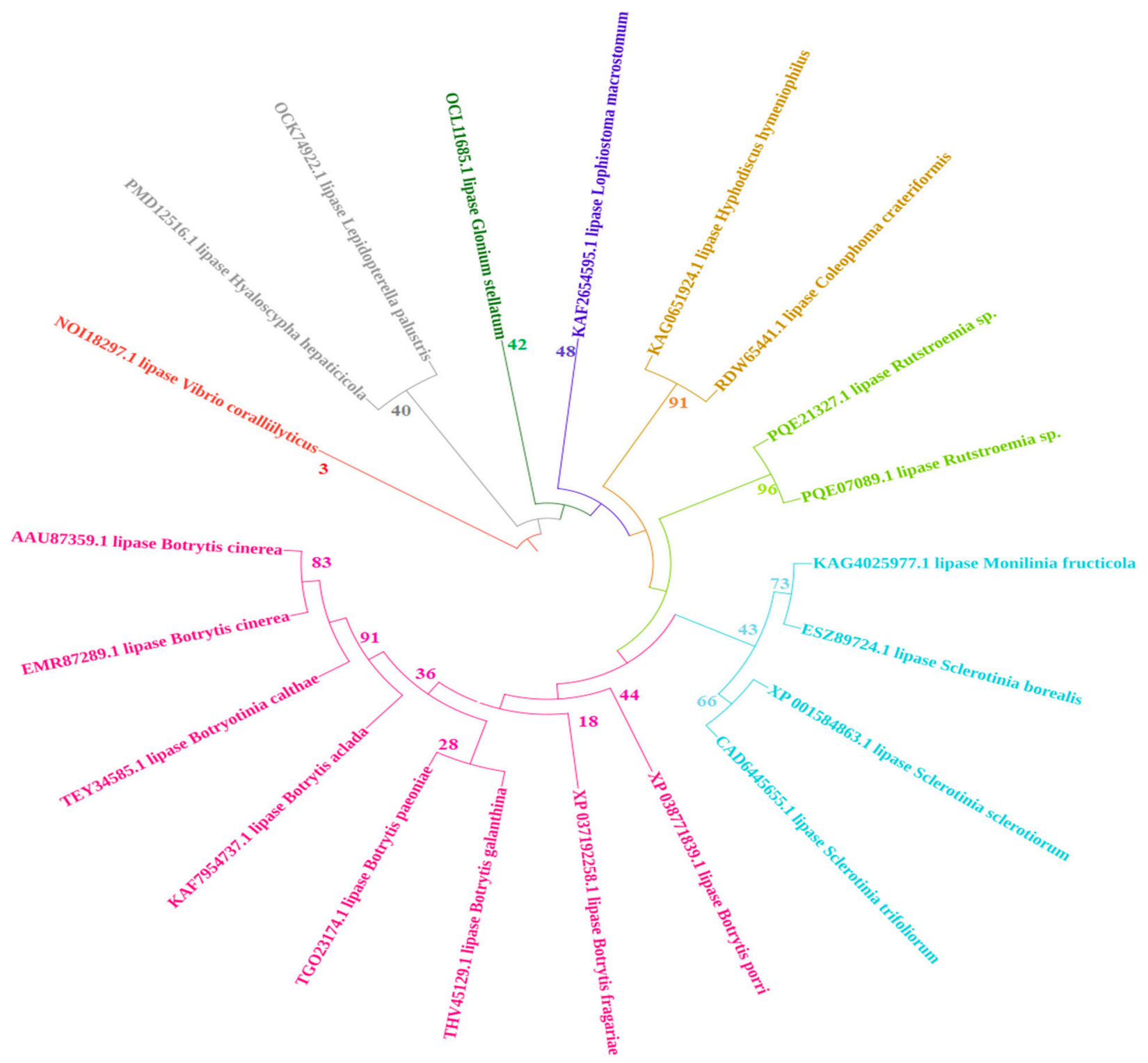

Figure 2. Phylogenetic tree of $B$. cinerea lipase. Phylogenetic rooted tree of $B$. cinerea lipase is constructed using maximum likelihood method.

\subsection{Signal Peptide Removal}

For B. cinerea lipase, the signal peptide cleavage site was found between the 27 and 28 aa residues, as depicted in Figure 3. The Sec/SPI score was 0.9965, which indicated the presence of a signal peptide in the protein sequence of $B$. cinerea lipase. Similarly, the Philius web server also predicted the same cleavage site. 
SignalP-5.0 prediction (Eukarya): Sequence

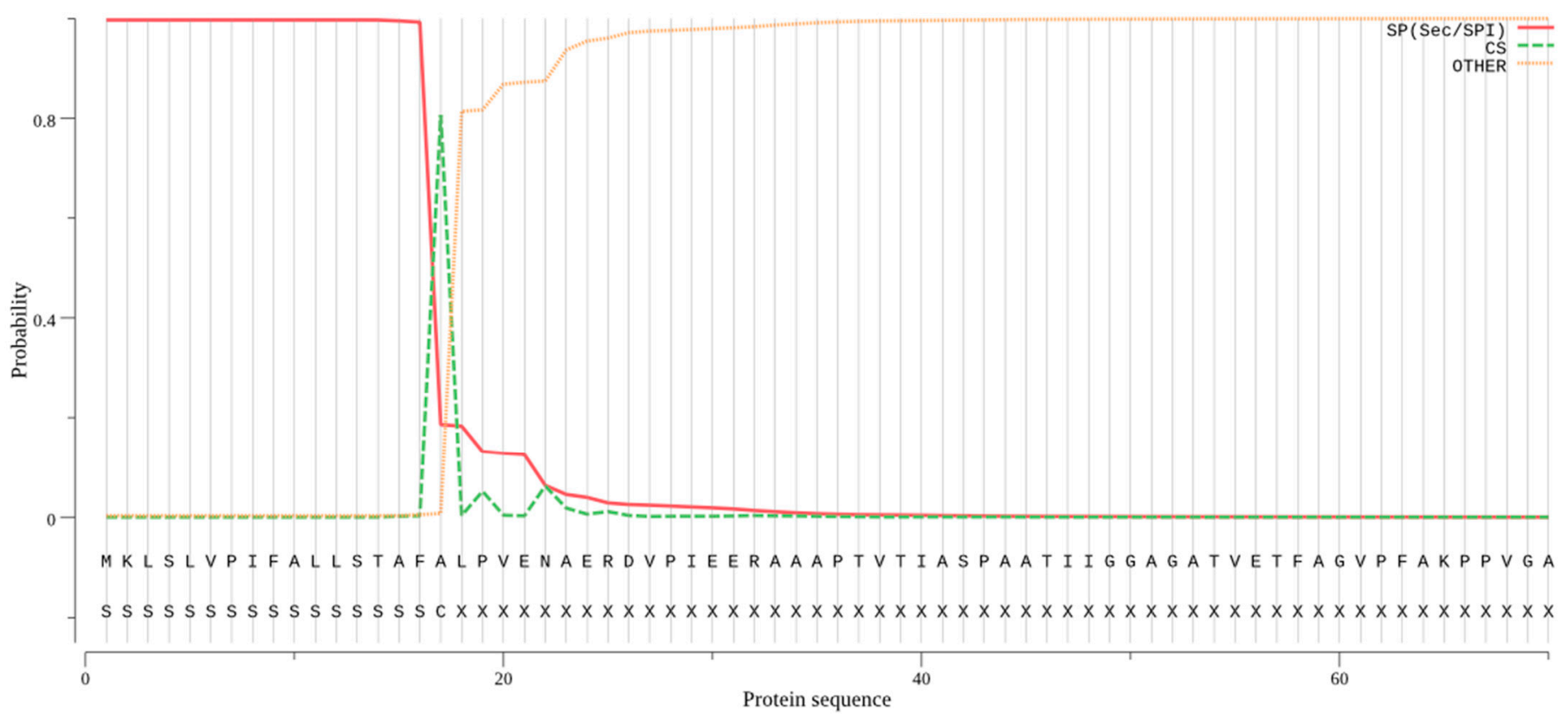

Figure 3. Signal peptides of B. cinerea lipase are presented by using SignalP server. Signal peptides are present in B. cinerea protein that direct it to the subcellular localization site. The signal peptide is 27 aa residues long in the lipase protein sequence.

\subsection{Prediction of Secondary Structure of B. cinerea Lipase}

The secondary structure of lipase by PSIPRED is shown in Figure 4. A total of 18 helices were found. Six beta sheets were also found.

\begin{tabular}{|c|c|c|c|}
\hline Strand & Helix & Coil & Disordered \\
\hline Disordered, protein binding & Putative Domain Boundary & Membrane Interaction & Transmembrane Helix \\
\hline Extracellular & Re-entrant Helix & Cytoplasmic & Signal Peptide \\
\hline
\end{tabular}

Figure 4. Alpha helices in B. cinerea lipase. Alpha helices have been depicted by PSIPRED in B. cinerea lipase. A total of eighteen alpha helices were present in the protein structure.

\subsection{Prediction of Tertiary Structure of B. cinerea Lipase}

All the models were evaluated for the Q-mean, the ERRAT score, and Ramachandran plots of the predicted models. The scores for the top models of each method used for prediction are provided in Table 2. Robetta-TR model 1 had the best scores among all the tested models, as its ERRAT score graph and Ramachandran plots show in Figures 5 and 6. 
Therefore, Robetta-TR model 1 was further refined using the 3Drefine webserver. The predicted model is shown in Figure 7. Furthermore, the predicted model of the B. cinerea lipase was superimposed on the sterol esterase of Ohiostoma piceae, as shown in Figure 7. A similarity of $80 \%$ was selected as the default, and the RMSD values for the alpha carbons and backbone were 2.90 and 2.86, respectively. The binding sites, predicted by CASTp, are shown in Figure 8.

Table 2. Thread-based and ab initio scores for protein modeling. Scores obtained from output models of I-TASSER, Phyre2, and Robetta ab initio TR are shown. Robetta-TR models with best scores were selected.

\begin{tabular}{|c|c|c|c|c|c|c|c|}
\hline \multirow[b]{2}{*}{ Protein Type } & \multirow[b]{2}{*}{ Method/Tool } & \multirow[b]{2}{*}{ Method } & \multirow[b]{2}{*}{ ERRAT } & \multirow[b]{2}{*}{ Q-Mean } & \multicolumn{3}{|c|}{ Ramachandran Plot } \\
\hline & & & & & Outlier (\%) & $\begin{array}{c}\text { Allowed Region } \\
(\%)\end{array}$ & $\begin{array}{c}\text { Favorable Region } \\
(\%)\end{array}$ \\
\hline \multirow{4}{*}{$\begin{array}{l}\text { B. cinerea } \\
\text { Lipase }\end{array}$} & ITASSAR_1 & Thread-Based & 68.4 & 0.5 & 3.6 & 7.8 & 55.0 \\
\hline & PHYRE_2 & Normal & 56.5 & 0.3 & 2.2 & 18.4 & 50.0 \\
\hline & ROBETTA_Ab & AB-initio & 72.4 & 0.35 & 0.9 & 23.2 & 74.0 \\
\hline & ROBETTA_TR & Thread-Based & 93.2 & 0.68 & 1.5 & 14.4 & 83.0 \\
\hline
\end{tabular}

Program: ERRAT2

File: Refined_model1_16234092615899.pdb

Chain\#:A

Overall quality factor**: 93.236

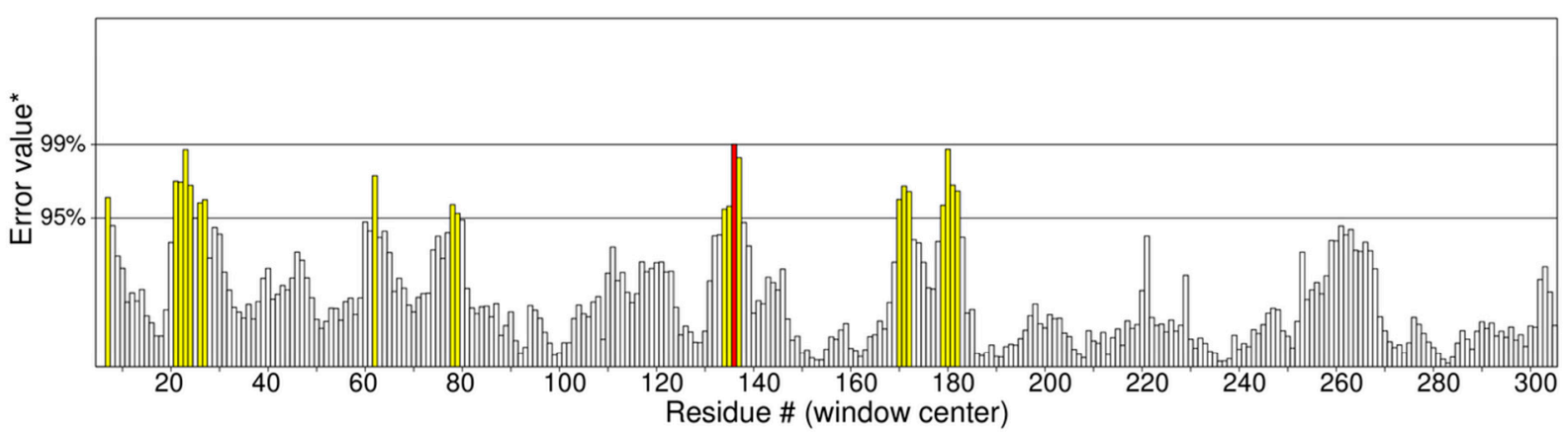

*On the error axis, two lines are drawn to indicate the confidence with which it is possible to reject regions that exceed that error value. "*Expressed as the percentage of the protein for which the calculated
error value falls below the $95 \%$ rejection limit. Good high resolution error value falls below the $95 \%$ rejection limit. Good high resolution
structures generally produce values around $95 \%$ or higher. For lower
resolutions ( 2.5 to $3 A$ ) the average overall quality factor is around $91 \%$.

Figure 5. ERRAT plot of overall quality factor of modeled structure of B. cinerea lipase is shown. The graph represents error values of model residues predicted by ERRAT. The " $x$ " axis indicates the amino acid sequences of lipase, while the " $y$ " axis presents the error values. 


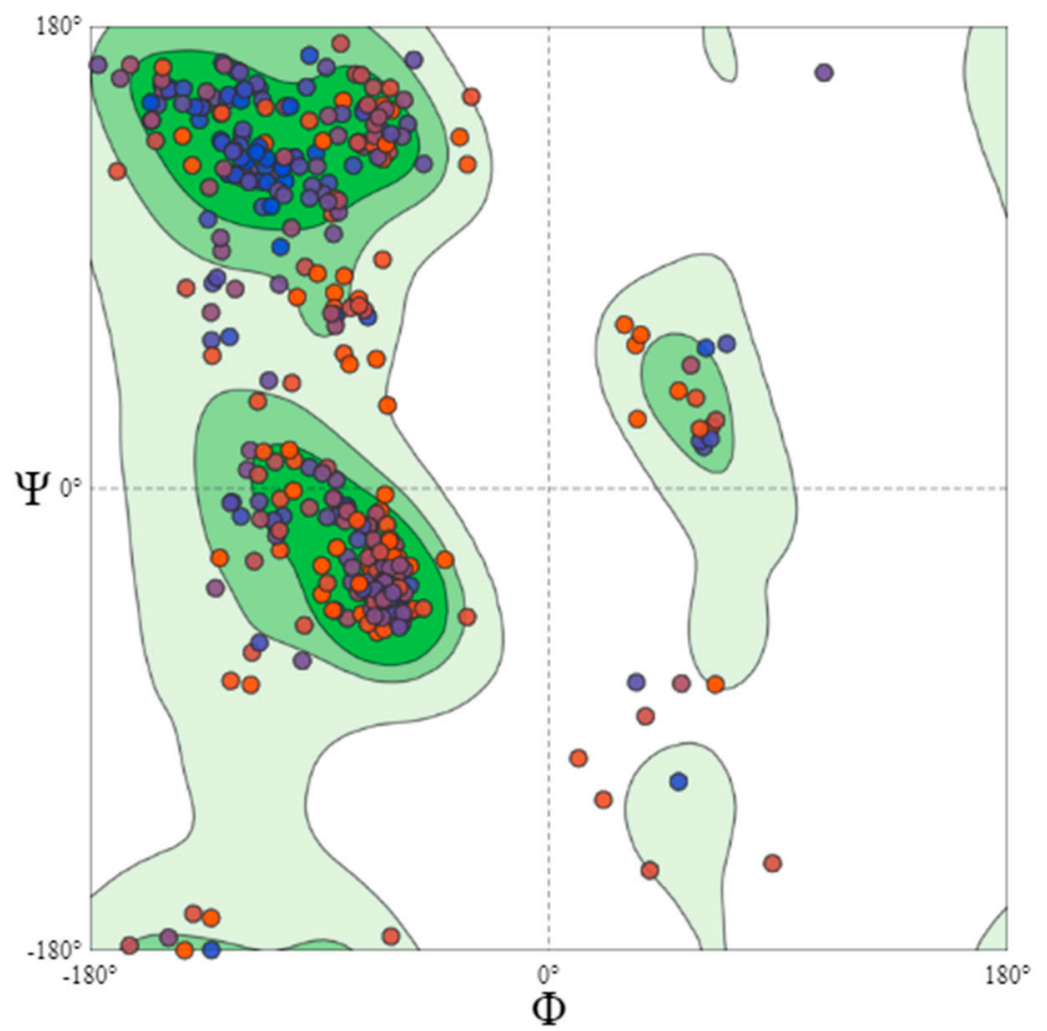

Figure 6. Ramachandran plot of Robetta-TR protein model (final model selected). The Ramachandran plot of modeled protein, representing $83.0 \%$ of residues in most favoured regions, $14.4 \%$ in additional allowed regions, $1.1 \%$ in generously allowed regions, and $1.5 \%$ in the disallowed regions.
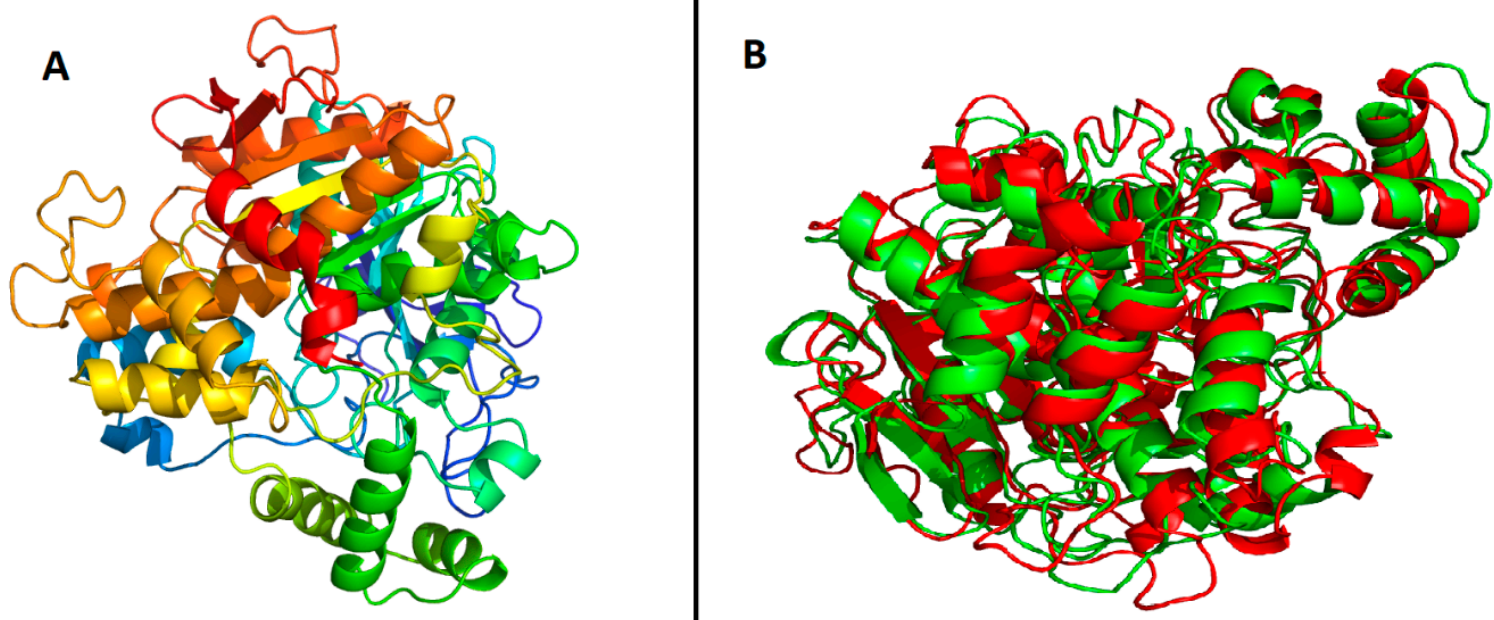

Figure 7. Refined 3D model and superimposed structure: (A) represents 3D-refined tertiary structure of B. cinerea lipase; and (B) represents its superimposition with crystal structure of Ohiostoma piceae sterol esterase (PDB ID 4be4). 


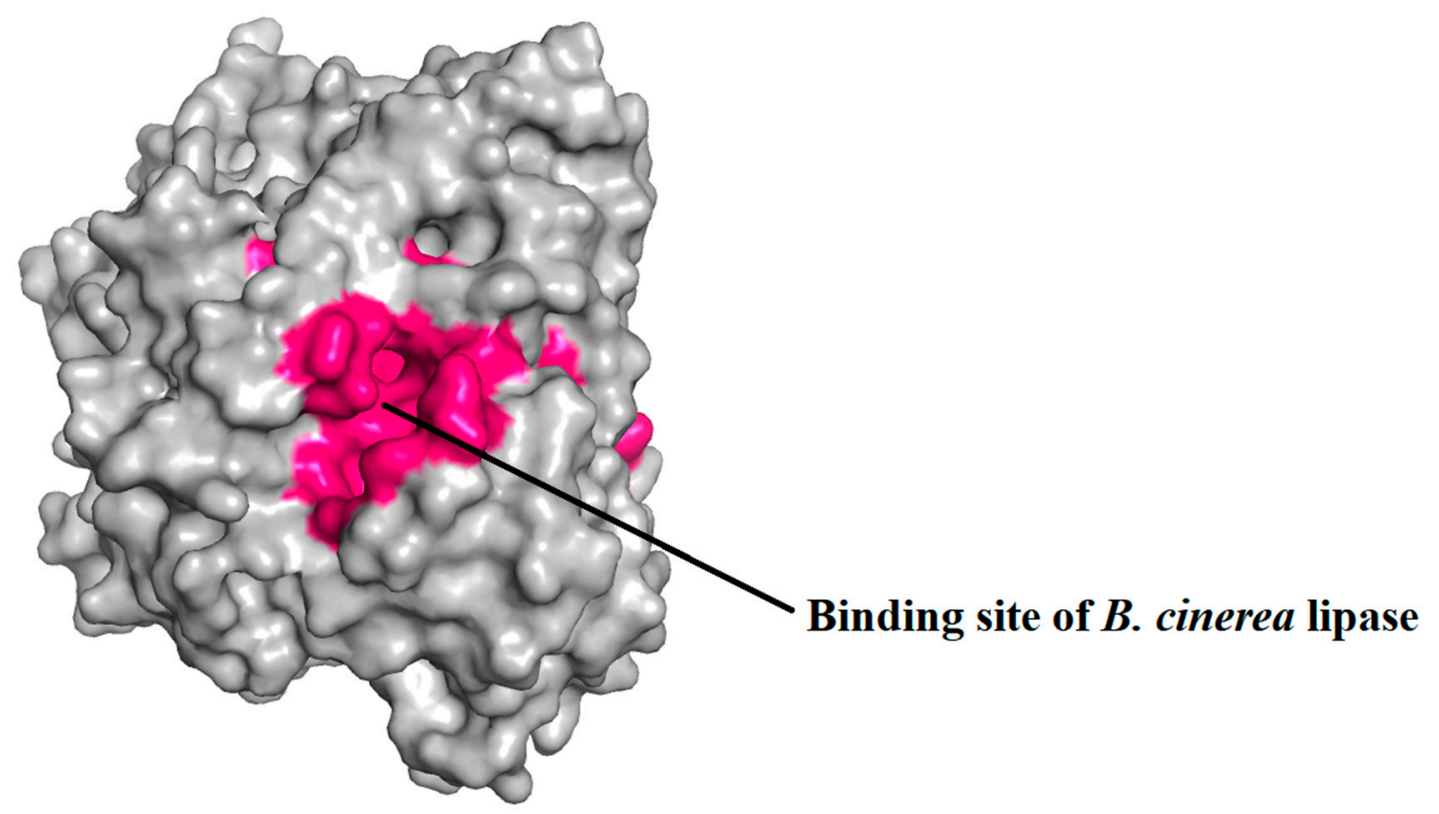

Figure 8. Binding pocket of B. cinerea lipase. Binding pocket of B. cinerea lipase that has been predicted depicted by pink color. The binding pocket is very big and deep, consisting of a large number of amino acid residues.

\subsection{Prediction of Binding Pocket Site of Protein}

The binding sites of the protein were identified by CASTp, as represented in Figure 9, and were embedded inside the proteins. The protein had large and deep binding sites, consisting of 100 amino acid residues.

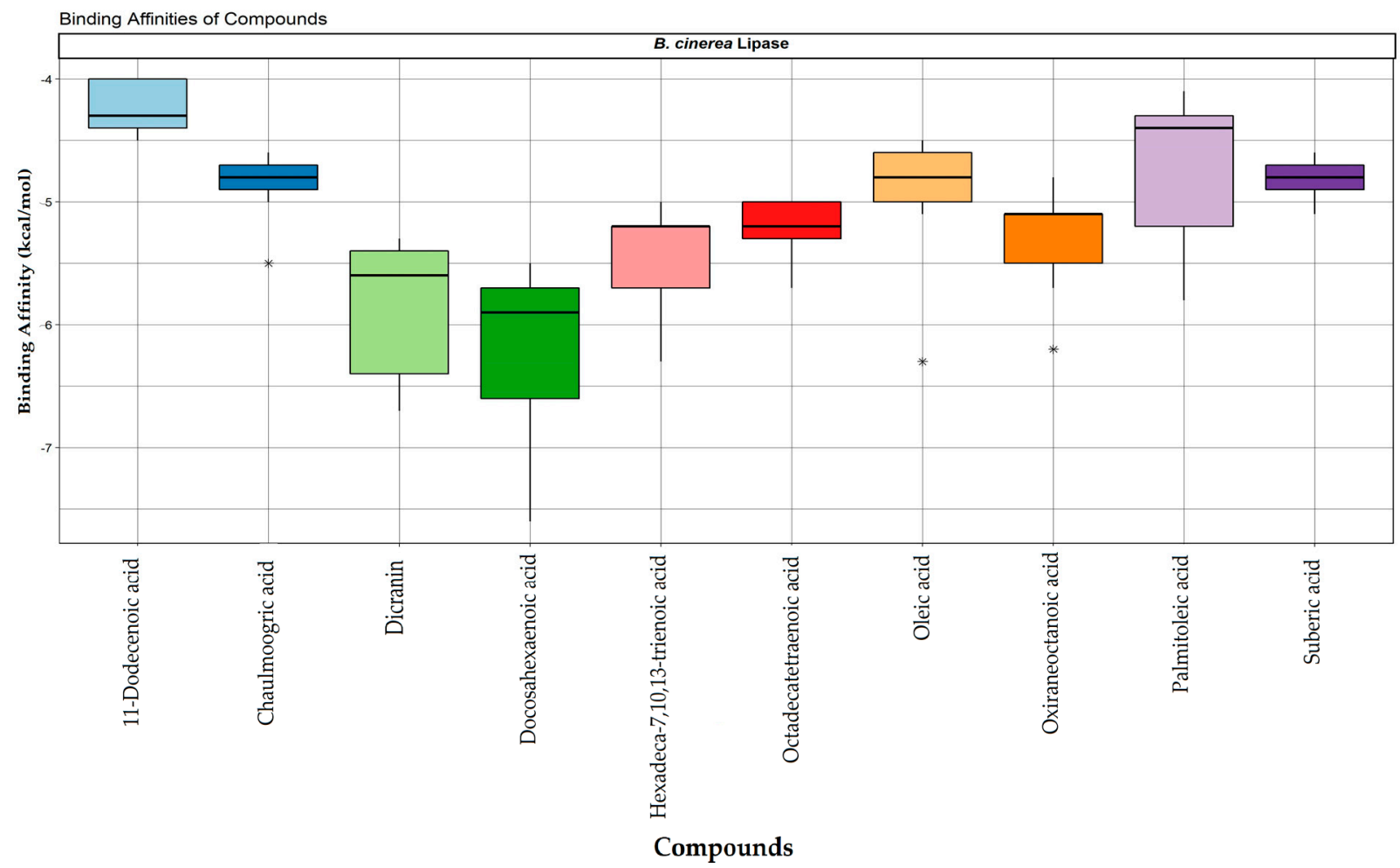

Figure 9. Boxplot of the top ten plant triglycerides. The top ten plant triglycerides showed the differential binding affinities pattern. Dicranin, docosahexaenoic acid, and hexadeca-7,10,13-trienoic acid showing the smallest binding energy values, which dictate a stronger binding interaction with the lipase. 


\subsection{Molecular Docking of Lipase with Plant Triglycerides}

The top ten triglycerides having the least number of binding affinities associated with B. cinerea lipase were selected, and their binding affinities are shown as boxplots in Figure 9 . The IUPAC names, molecular weights, PubChem IDs, and the numbers of hydrogen and hydrophobic interactions are shown in Table 3. Docosahexaenoic acid possessed the lowest binding energy $(-7.6 \mathrm{kcal} / \mathrm{mol})$, followed by dicranin $(-6.7 \mathrm{kcal} / \mathrm{mol})$, and hexadeca7,10,13-trienoic acid $(-6.3 \mathrm{kcal} / \mathrm{mol})$. The protein-ligand interactions of the top three triglycerides, including docosahexaenoic acid, dicranin, and hexadeca-7,10,13-trienoic acid, are represented in Figure 10. Docosahexaenoic acid and hexadeca-7,10,13-trienoic acid both contained two hydrogen bonds, while dicranin had three hydrogen bonds. Docosahexaenoic acid and dicranin both had fourteen hydrophobic interactions, while hexadeca-7,10,13-trienoic acid had 9 hydrophobic interactions with $B$. cinerea lipase. The protein-ligand complexes were proceeded by molecular dynamics simulation in order to explore conformational energy landscapes.

Table 3. The list of top ten compounds showing the lowest binding affinities with B. cinerea lipase. Plant fatty acids with molecular weights and molecular formulas, binding affinites, hydrgen bonds, and hydrophobic interactions are represented in the table.

\begin{tabular}{|c|c|c|c|c|c|c|}
\hline Compound & IUPAC Names & PubChem ID & $\begin{array}{l}\text { Molecular } \\
\text { Formula }\end{array}$ & $\begin{array}{l}\text { Hydrogen } \\
\text { Bonds }\end{array}$ & $\begin{array}{l}\text { Hydrophobic } \\
\text { Interactions }\end{array}$ & $\begin{array}{l}\text { Binding } \\
\text { Affinities }\end{array}$ \\
\hline Oxiraneoctanoic acid & $\begin{array}{c}\text { 8-(3-oct-2-enyloxiran-2- } \\
\text { yl)octanoic } \\
\text { acid }\end{array}$ & 1929 & $\mathrm{C}_{18} \mathrm{H}_{32} \mathrm{O}_{3}$ & 3 & 10 & -5.7 \\
\hline Docosahexaenoic acid & $\begin{array}{c}\text { (4Z,7Z,10Z,13Z,16Z,19Z)- } \\
\text { docosa-4,7,10,13,16,19- } \\
\text { hexaenoic } \\
\text { acid }\end{array}$ & 445580 & $\mathrm{C}_{22} \mathrm{H}_{32} \mathrm{O}_{2}$ & 2 & 14 & -7.6 \\
\hline $\begin{array}{l}\text { Hexadeca-7,10,13- } \\
\text { trienoic } \\
\text { acid }\end{array}$ & $\begin{array}{c}\text { hexadeca-7,10,13-trienoic } \\
\text { acid }\end{array}$ & 2826712 & $\mathrm{C}_{16} \mathrm{H}_{26} \mathrm{O}_{2}$ & 2 & 9 & -6.3 \\
\hline Suberic acid & octanedioic acid & 10457 & $\mathrm{C}_{8} \mathrm{H}_{14} \mathrm{O}_{4}$ & 2 & 4 & -5.0 \\
\hline Chaulmoogric acid & $\begin{array}{l}\text { 13-cyclopent-2-en-1- } \\
\text { yltridecanoic } \\
\text { acid }\end{array}$ & 72853 & $\mathrm{C}_{18} \mathrm{H}_{32} \mathrm{O}_{2}$ & 1 & 10 & -5.0 \\
\hline 11-Dodecenoic acid & $\begin{array}{c}\text { (8Z,10E,12Z)-octadeca- } \\
\text { 8,10,12-trienoic } \\
\text { acid }\end{array}$ & 125207 & $\mathrm{C}_{12} \mathrm{H}_{22} \mathrm{O}_{2}$ & 0 & 7 & -4.5 \\
\hline Palmitoleic acid & (Z)-octadec-9-enoic acid & 445638 & $\mathrm{C}_{16} \mathrm{H}_{30} \mathrm{O}_{2}$ & 1 & 12 & -5.8 \\
\hline Oleic acid & (Z)-octadec-9-enoic acid & 445639 & $\mathrm{C}_{16} \mathrm{H}_{34} \mathrm{O}_{2}$ & 1 & 13 & -5.1 \\
\hline Dicranin & $\begin{array}{c}\text { (9Z,12Z,15Z)-octadeca- } \\
\text { 9,12,15-trien-6-ynoic } \\
\text { acid }\end{array}$ & 44584408 & $\mathrm{C}_{18} \mathrm{H}_{26} \mathrm{O}_{2}$ & 3 & 14 & -6.7 \\
\hline Octadecatetraenoic acid & $\begin{array}{c}\text { (9Z,11Z,13E,15E)-4- } \\
\text { oxooctadeca-9,11,13,15- } \\
\text { tetraenoic } \\
\text { acid }\end{array}$ & 5312915 & $\mathrm{C}_{18} \mathrm{H}_{26} \mathrm{O}_{3}$ & 3 & 10 & -5.3 \\
\hline
\end{tabular}

\subsection{Molecular Dynamics Simulations}

The molecular dynamics simulations of the top three complexes revealed structure stability and fluctuations during the $20 \mathrm{~ns}$ simulations. Hexadeca-7,10,13-trienoic acid showed minor fluctuations at the start, but stabilized from $4.5 \mathrm{~ns}$ to $11.5 \mathrm{~ns}$, according to the RMSD values shown in Figure 11. The structure fluctuated from $11.5 \mathrm{~ns}$ to $14 \mathrm{~ns}$ and again stabilized onwards, whereas the dicranin complex with the lipase was only stable from $9 \mathrm{~ns}$ to $17 \mathrm{~ns}$. It fluctuated at the start and end of the simulation. Doxosahexaenoic acid was unstable initially, but then stabilized after $\sim 8500 \mathrm{ps}$, and remained stable to $\sim 18,500 \mathrm{ps}$. 


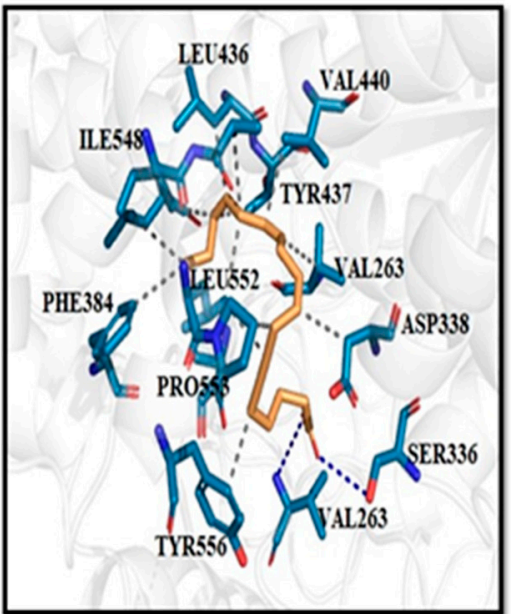

Dicranin

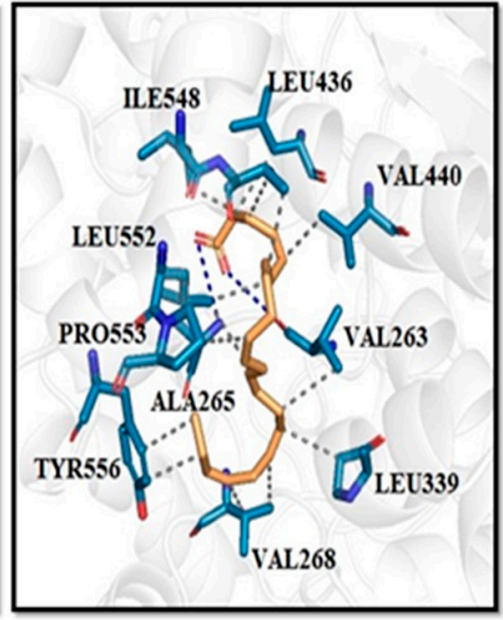

Docsahexanoic acid
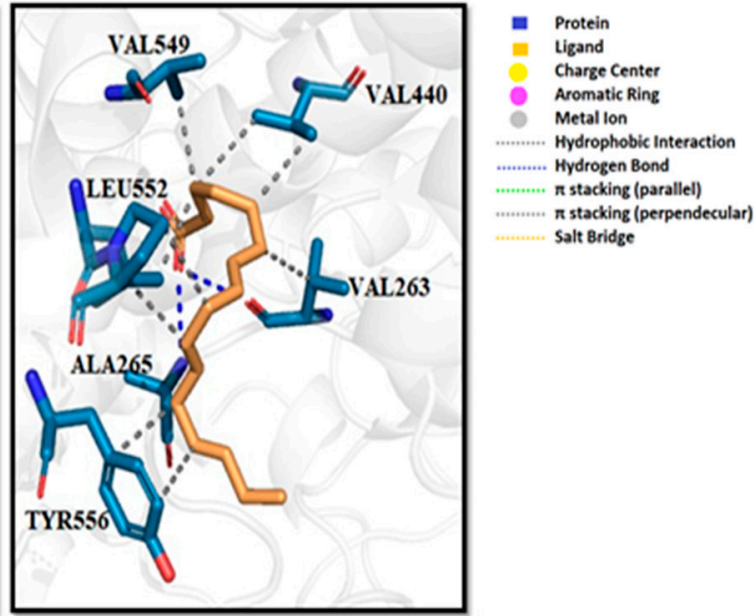

Hexadeca-7,10,13-trienoic acid

Figure 10. Protein-ligand interactions using PLIP server. Protein-ligand interactions of dicranin, docosahexanoic acid, and hexadeca-7,10,13-trienoic acid with B. cinerea lipase are represented, highlighting the key residues involved in the interaction.

\section{RMSD}

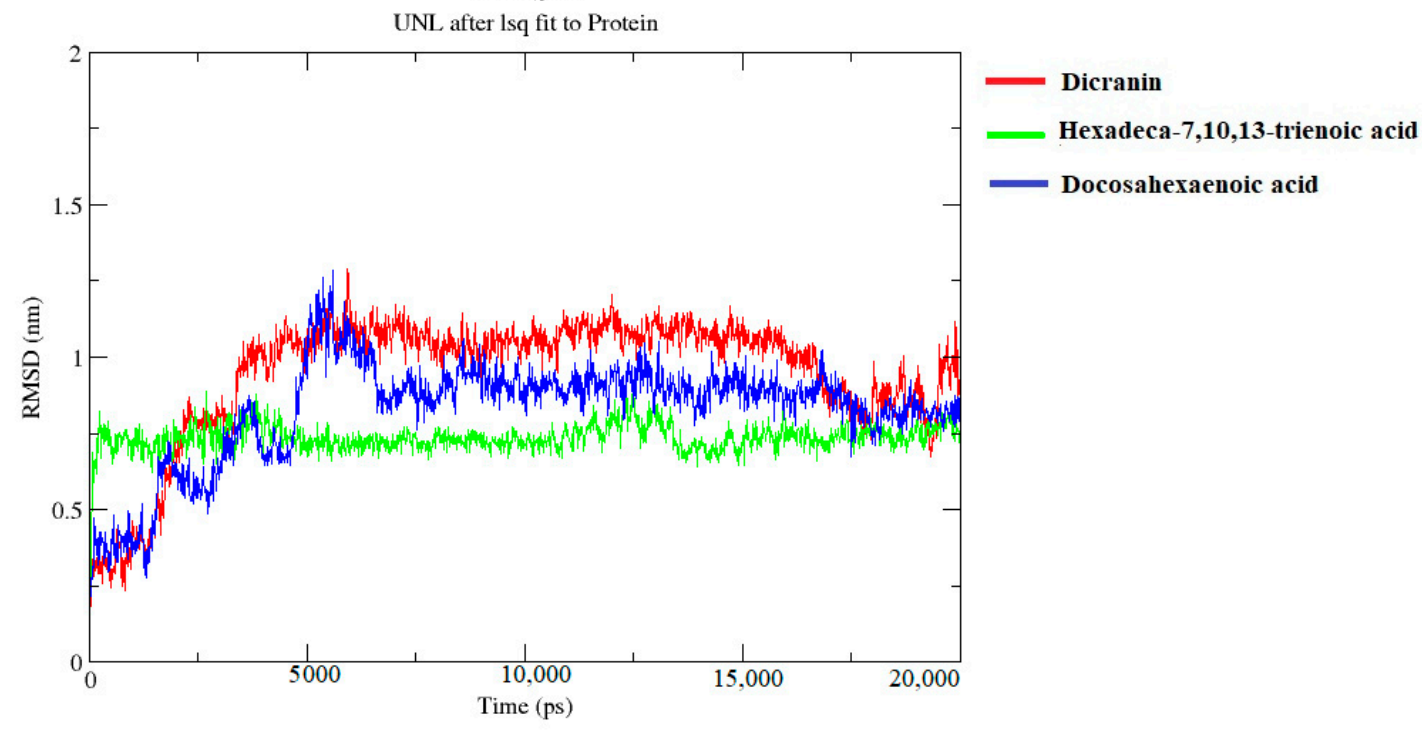

Figure 11. Root mean square deviation (RMSD) plot interactions with dicranin (red), docosahexaenoic acid (blue), and hexadeca-7,10,13-trienoic acid (green) complexes, with protein's backbone.

The radius of gyration represents the compactness of the structure in Figure 12. The structures fluctuated between $2.40 \mathrm{~nm}$ and $2.50 \mathrm{~nm}$. The $\mathrm{Rg}$ for hexadeca-7,10,13-trienoic acid was lower at the start, representing that the structure is compact, wheras the Rg values for docosahexaenoic acid and dicranin showed overall fluctuations. However, in the end, the compactness was reduced as the Rg value increased.

The lipase complex with docosahexaenoic acid became more compact towards the end of the simulation. Similarly, the compactness of the lipase complex with dicranin increased towards the end of the simulation.

The root mean square fluctuation of docosahexaenoic acid, dicranin, and hexadeca7,10,13-trienoic acid in the complex showed stability, as shown in Figure 13. Only a few residues at the start fluctuated, but overall the structure was stable. Other minor fluctuations were less than $0.75 \mathrm{~nm}$, indicating the stability. 


\section{Radius of gyration (total and around axes)}

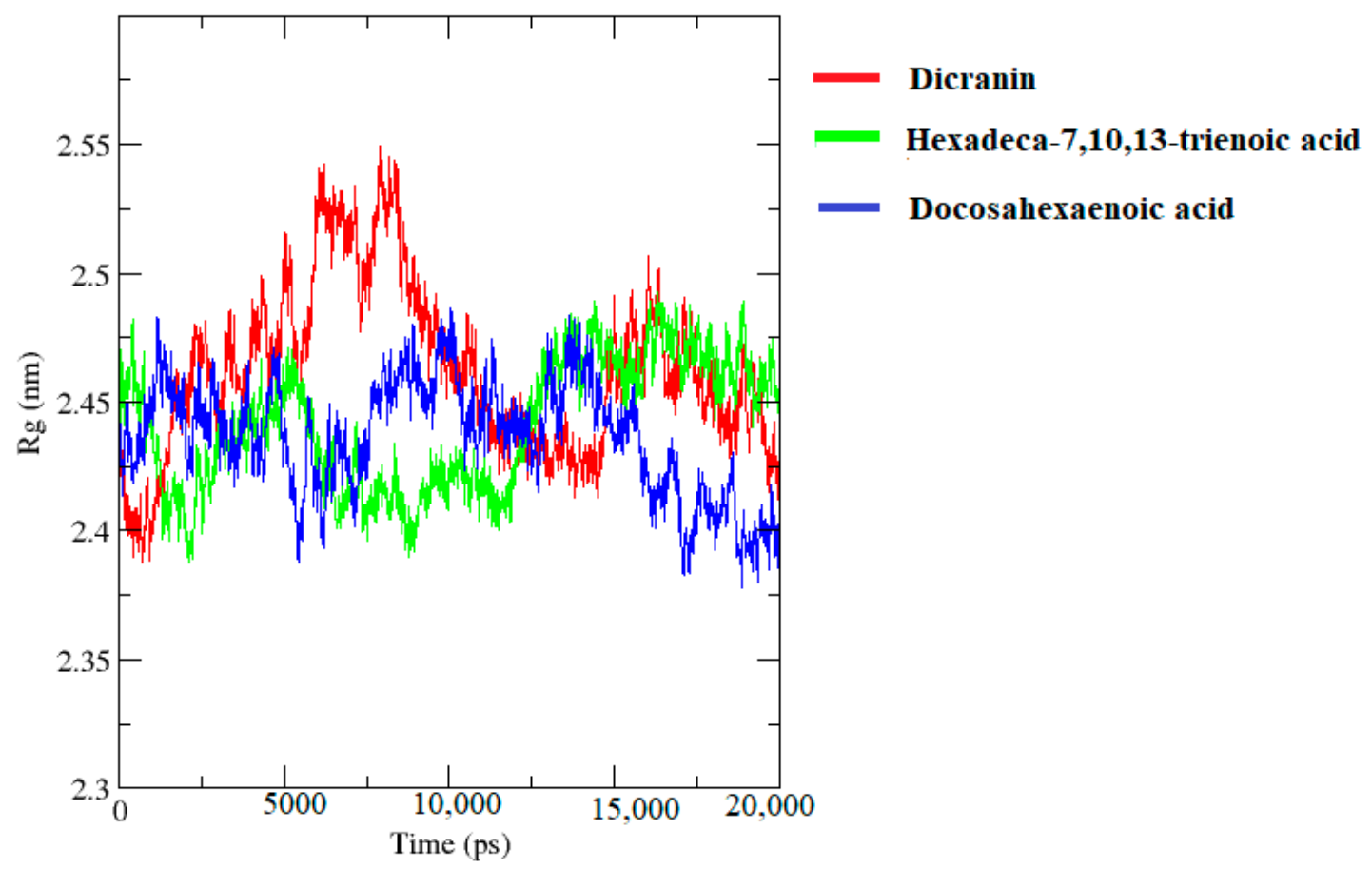

Figure 12. Radius of gyration ( $\mathrm{Rg}$ ). Radius of gyration for predicting the compactness of the protein structure of B. cinerea lipase, complexed with dicranin (red), docosahexaenoic acid (blue), and hexadeca-7,10,13-trienoic acid (green), are represented.

RMS fluctuation

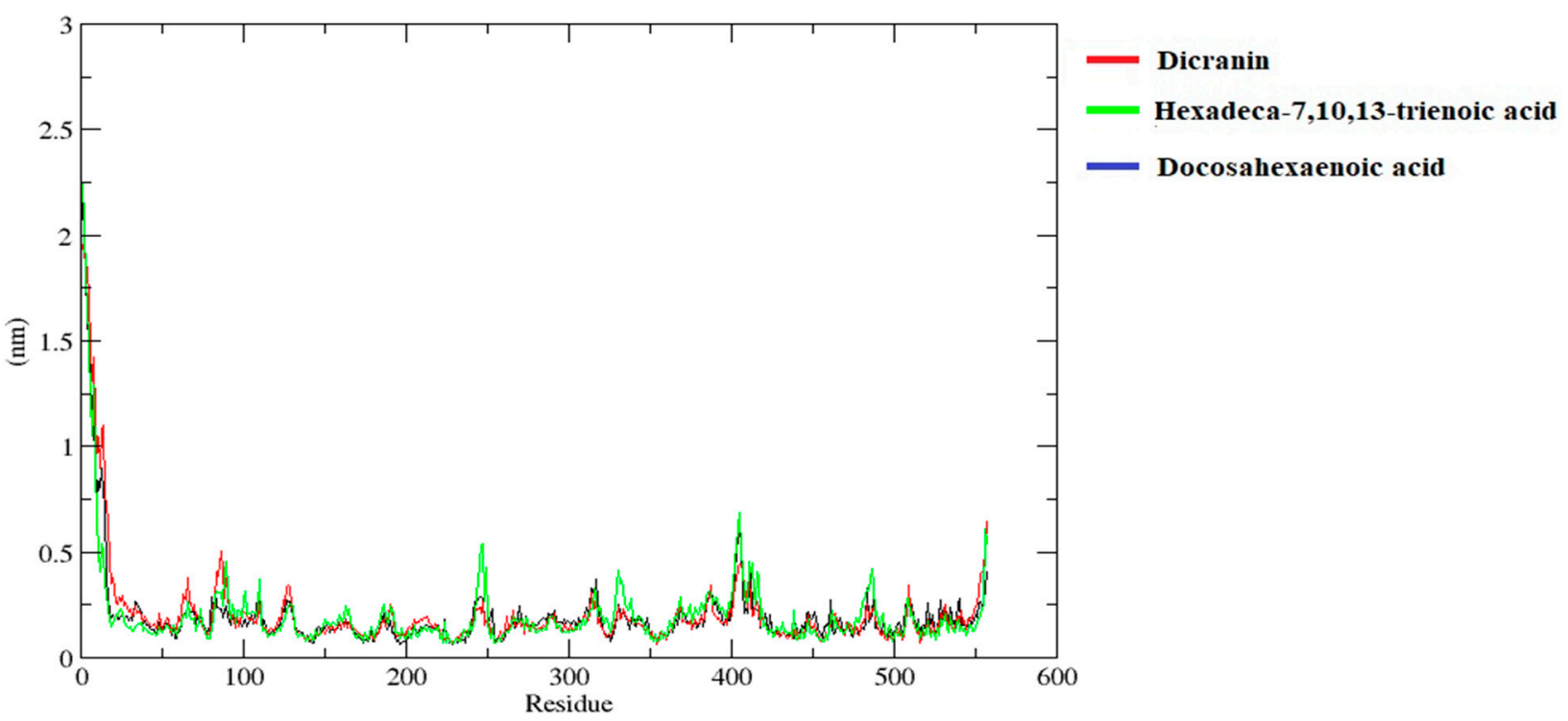

Figure 13. Root mean square fluctuations (RMSF). RMSF plots are presenting the stability of the protein structure. RMSF of protein structure of $B$. cinerea lipase complex, with dicranin (red), docosahexaenoic acid (blue), and hexadeca-7,10,13-trienoic acid (green), are represented.

\section{Discussion}

Fungal lipases are advantageous over other microbial lipases because of their potential to utilize free fatty acids, monoglycerides, diglycerides, and triglycerides during the trans- 
esterification reaction at higher activity and maximum yields. These lipases can catalyze the reaction in nonaqueous media at lower temperatures, within shorter times, and ease mass biofuel production $[25,26]$. Approximately more than $80 \%$ plant triglycerides are used for diesel fuels because of their availability, higher heat content, biodegradability, lower sulfur content, renewability, and lower aromatic content $[27,28]$. Current research reveals that plant triglycerides, such as dicranin, docosahexaenoic acid, and hexadeca-7,10,13-trienoic acid, were potent feedstock for $B$. cinerea-lipase-mediated biofuel production.

B. cinerea lipase represent a 50 to $60 \%$ homology with lipases from filamentous fungi, and a 35 to $45 \%$ homology with lipases from C. rugosa and G. candidum [23]. In the current study, the lipases from two different strains of Botrytis represented a $100 \%$ homology. Hence, the lipases from any Botrytis strain can contribute in similar manners for biofuel production, as these are very similar.

Because of the great advancements in in silico approaches, this study was designed to decipher the interactions between $B$. cinerea lipase and the plant triglycerides that have been previously reported [29]. Recently, fungal lipases obtained from Mucor circinelloides, f. circinelloides, and Rhizopus oryzae interacting with triglycerides were also modeled using computational approaches [30]. The three-dimensional protein structures of various lipases from ascomycetes, such as Ophiostoma piceae, Melanocarpus albomyces, and Candida rugosa, have been resolved [31-33]. However, B. cinerea lipase has not been structurally characterized. In earlier studies, protein homology modeling was used for the prediction of the tertiary structure for those not already resolved [34]. For this purpose, SWISS MODEL was chosen for homology modeling, and the resultant homology was found to be $58 \%$ with Ophiostoma piceae sterol esterase. The obtained value is higher than other recently modeled lipases: 32\% for Arabidopsis thaliana lipase, and 32.11\% for Streptomyces rimosus lipase [35,36]. The protein modeling for $B$. cinerea lipase was also performed using thread-based and ab initio approaches after first removing 17 amino acids from the signal peptide. I-TASSER, Phyre2, and the Robetta ab initio and TR methods were chosen for the determination of the protein tertiary structure, but the final model was selected from the Robetta-TR method having the highest scores, as shown in Table 2.

An ERRAT-based statistical analysis was performed for the quality validation of the selected model. This program analyses the nonbonded interaction patterns of various types of atoms [37]. The overall quality factor assigned to the B. cinerea lipase model was 93.236\%, as shown in Figure 6, which is a good value for a predicted protein structure. Similarly, the quality factor for Glaciozyma antarctica lipase was found to be $91.3 \%$ [38]. A Q-mean-based quality estimation was also performed, and the best fit model represented a 0.68 value, which is above the 0.52 reported for Nocardiopsis alba lipase modeling [39]. Therefore, the quality of the selected model was further assessed by a Ramachandran plot. The Ramachandran plot obtained showed that $83.0 \%$ of the residues were found in the most favored regions. A total of $14.4 \%$ of the residues were in the additional allowed regions, $1.1 \%$ residues were found in the generally allowed regions, and $1.5 \%$ of the residues were found in the disallowed regions, as shown in Figure 7. Similarly, the crystal structure of feruloyl esterase from $A$. niger represented $81.1 \%$ of the residues in the most favored regions, $15.8 \%$ in the additional allowed regions, and $0.9 \%$ in the disallowed regions $[34,39]$.

The isoelectric point predicted for $B$. cinerea lipase was 4.93, which is below 7.0, an indication of its acidic nature, as was reported very recently for $\beta$-glucosidase and xylanase from Trichoderma asperellum [40,41]. The instability index value was $36.20 \%$, validating the stable lipase, while the aliphatic index was $92.21 \%$, proving the thermal stability of the lipase because the higher aliphatic index (>40\%) presents thermostable tertiary protein [42]. The grand average of the hydropathicity (GRAVY) indicates the sum of the hydropathy values of the protein. Negative and positive GRAVY values indicate hydrophilicity and hydrophobicity, respectively [43]. The values for the negatively and positively charged residues were 38 and 30, respectively. These values correspond to the hydrophilic or hydrophobic nature of the protein. The B. cinerea lipase protein had a positive GRAVY value, which corresponds to its hydrophobic nature, while the GRAVY values reported 
for the recombinant lipases, EXANL1 and A. niger F044 lipase lip1, were 0.025 and 0.05, respectively, which also corresponds to a hydrophobic nature [40,44].

Finally, the top ten fatty acids were selected having the least number of binding affinities from 161 fatty acids docked with $B$. cinerea lipase. The resultant affinity energy values of the lipase with triglycerides were consistent, and even greater than recently reported in the literature. Lower affinity values exhibit higher interactions between the fatty acid and the lipases $[45,46]$. The docking affinity values of the lipase, with different fatty acids, such as palmitic acid, stearic acid, lauric acid, and myristic acid, were -5.9 , $-3.7,-3.5$, and $-3.2 \mathrm{kcal} / \mathrm{mol}$, respectively. The current resultant affinity values for docosahexaenoic acid, dicranin, and hexadeca-7,10,13-trienoic acid are -7.6, -6.7, and $-6.3 \mathrm{kcal} / \mathrm{mol}$, respectively. Therefore, the resultant values confirm that $B$. cinerea lipase shows promising interactions with plant triglycerides for biofuel production.

The molecular docking results were further assessed for quality estimation through docking accuracy and screening enrichment procedures [17]. Lipases contain the consensus sequence, G-X-S-X-G, which presents the active residue-forming catalytic site. The residues include active glycine $(G)$ and serine $(S)$, in combination with any other $(X)$ [47]. The active residues shown in Figure 1 present G-X-S-X-G as a conserved motif, whereas the active residues of the $B$. cinerea lipase were comprised of the binding pockets of 100 amino acid residues containing the G-S-X-S-X-G motif, from residue no. 225 to 232, as predicted by DoGSiteScorer [48] and CASTp analysis [49].

The catalytic activity of hydrolases is known to depend upon the transition state stability caused by the hydrogen bonds involved. To assess the transition state stability, protein interactions with the top three ligands, docosahexaenoic acid, dicranin, and hexadeca-7,10,13-trienoic acid, were predicted through molecular docking. These interactions represent the active sites of $B$. cinerea lipase in the form of amino acid residues, which were directly interacting with ligands, accompanied by a number of hydrogen bonds and hydrophobic interactions, as shown in Figure 10. Docosahexaenoic acid has two hydrogen bonds interacting with Val 263 and Ala 265, and fourteen hydrophobic interactions. Moreover, hexadeca-7,10,13-trienoic acid also has two hydrogen bonds interacting with Val 263 and Ala 265, and nine hydrophobic interactions, whereas dicranin has three hydrogen bonds interacting with Val 286 and Ser366, and fourteen hydrophobic interactions with $B$. cinerea lipase. These results were in accordance with the reported studies where lipase-based transesterification depended on three hydrogen bonds for the stable transition state $[50,51]$. Hence, protein ligand complexes provide valuable information about the overall interactions taking place at the molecular level.

Molecular dynamics simulation was then chosen for providing insights into the dynamic structure and protein-ligand interactions for recognizing the structure-based functionality. The stability of these structures was confirmed by $20 \mathrm{~ns}$ simulation, through the MD simulation protocol [52]. The structural stability of the protein was evaluated through the RMSD and RMSF values of the given protein-ligand complex [53]. The compactness of the protein structure was indicated by the Rg value during the simulation, which has an inverse relation with the stability of the structure. B. cinerea lipase complex with dicranin and docosahexaenoic acid had compact structures towards the end of the simulation, whereas hexadeca-7,10,13-trienoic acid displayed reduced compactness towards the end. The RMSD values of dicranin presented stability from $9 \mathrm{~ns}$ to $17 \mathrm{~ns}$, docosahexaenoic acid showed overall stability from $5 \mathrm{~ns}$ to $15 \mathrm{~ns}$, with minor fluctuations at the start, whereas hexadeca-7,10,13-trienoic acid presented stabilized values from $4.5 \mathrm{~ns}$ to $11.5 \mathrm{~ns}$, which was the highest stability without any fluctuations. This indicates that, as the complex was stabilized, the lipase protein's compactness was reduced.

The RMSF values of the three ligands showed major fluctuations at the start, around 100, and minor fluctuations of around 250 and 400, which were less than 0.75. The MD simulation revealed that hydrogen bonds significantly affect the intermolecular recognition and active center for the lipase-substrate interaction. It can be concluded that dicranin, docosahexaenoic acid, and hexadeca-7,10,13-trienoic acid indicated overall stable structural 
confirmations with $B$. cinerea lipase. Hence, $B$. cinerea lipase can be utilized as a potent biocatalyst to process feedstock substrates for biofuel production.

\section{Materials and Methods}

Detailed flowchart of methodology is represented in Figure 14.

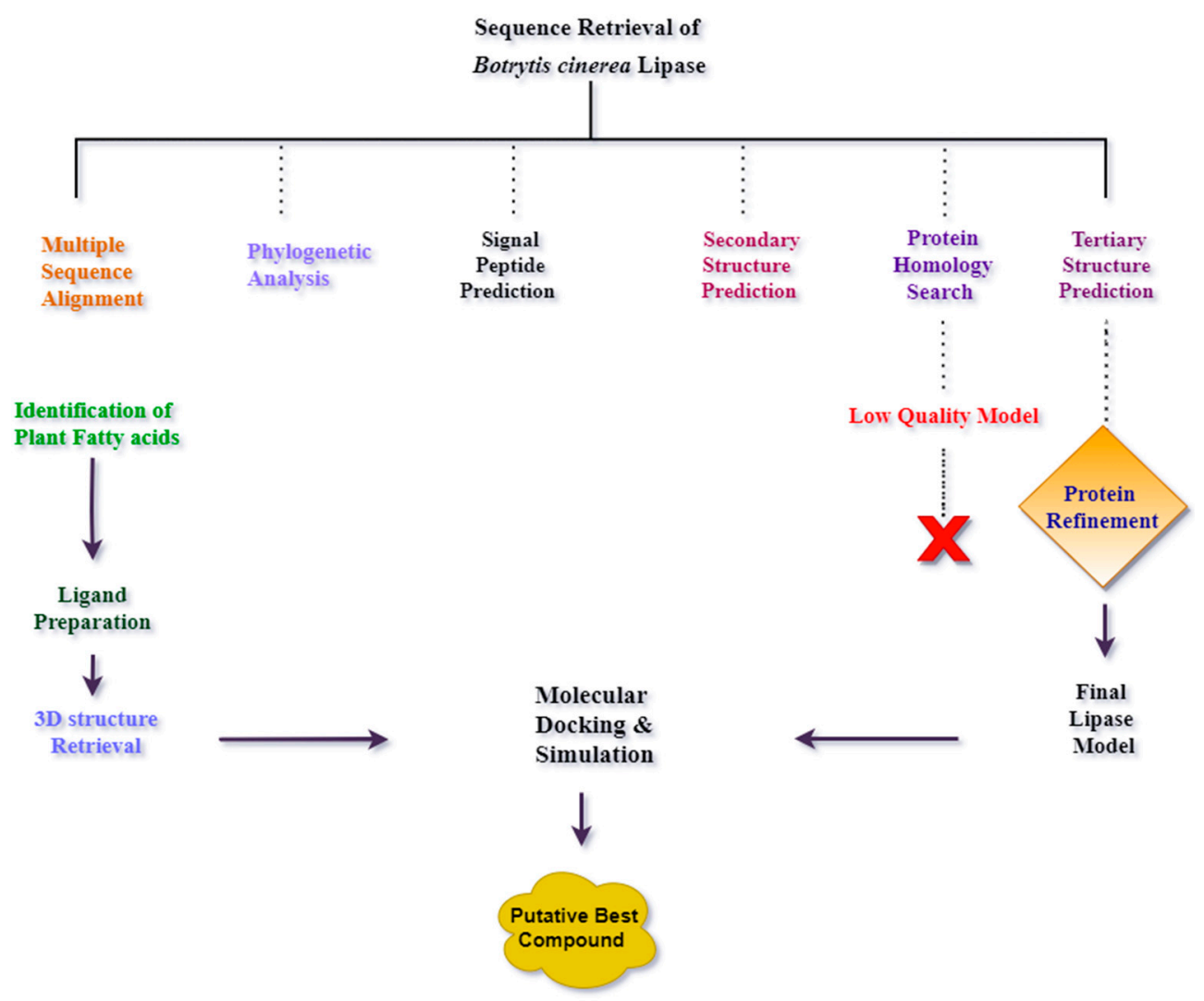

Figure 14. A detailed flowchart of the methodology used in this study.

4.1. Multiple Sequence Alignment and Phylogenetic Analysis of Lipase in Botrytis cinerea

The FASTA protein sequence of the lipase from Botrytis cinerea was retrieved from NCBI (Accession ID: AAU87359.1) to assess its function in biofuel production. Furthermore, protein sequences of Botrytis cinerea (EMR87289.1), Botryotinia calthae (TEY34585.1), Botrytis paeoniae (TGO23174.1), Botrytis aclada (KAF7954737.1), Botrytis galanthina (THV45129.1), Botrytis porri (XP 038771839.1), Botrytis fragariae (XP 037192258.1), Sclerotinia trifoliorum (CAD6445655.1), Sclerotinia borealis (ESZ89724.1), Monilinia fructicola (KAG4025977.1), Rutstroemia sp. (PQE07089.1 \& PQE21327.1), Coleophoma crateriformis (RDW65441.1), Hyphodiscus hymeniophilus (KAG0651924.1), Lophiostoma macrostomum (KAF2654595.1), Glonium stellatum (OCL11685.1), Lepidopterella palustris (OCK74922.1), Hyaloscypha hepaticicola (PMD12516.1), and Vibrio coralliilyticus (NOI18297.1) were retrieved from NCBI (https:/ / www.ncbi.nlm.nih.gov/, accessed on 5 June 2021) for multiple sequence alignment. The multiple sequence alignment of all these lipases was carried out using ClustalW plugin in MEGAX software (version 10.1.7) [54]. The pairwise and multiple alignment score for the gap opening penalty was 10.00 for both, whereas the gap extension penalty was 0.10 and 0.20 , respectively. Using multiple sequence alignment, phylogenetic analysis was performed using MEGAX (version 10.1.7) through the maximum likelihood statistical method and the Jones-Taylor-Thornton (JJT) model as an amino acid-based substitution model. The rooted tree was generated with the bootstrap values of 10,000 replicates. 


\subsection{Signal Peptide Prediction}

The FASTA protein sequence of the selected lipase (Accession ID: AAU87359.1) was analyzed for signal peptide prediction using the YRC Philius web server and SignalP 5.0 (http:/ / www.cbs.dtu.dk/services/SignalP/, accessed on 6 June 2021) [55,56].

\subsection{Protein Secondary Structure Prediction}

The secondary structure prediction was elucidated by PSIPRED workbench (http: / / bioinf.cs.ucl.ac.uk /psipred/, accessed on 6 June 2021). PSIPRED uses protein peptide sequences to analyze the three-dimensional secondary structure of protein, including the $\alpha$-helix, $\beta$-strand, and coil [57]. For structure prediction analysis, a FASTA sequence of $B$. cinerea lipase (AAU87359.1) was submitted in PSIPRED.

\subsection{Tertiary Structure Prediction of B. cinerea Lipase}

Previously, the crystal protein structure of lipase from B. cinerea was not resolved. A homology search was carried out using the BLASTp, and B. cinerea lipase showed $58 \%$ similarity with Ophiostoma piceae sterol esterase. A lower homology with the template crystal structure can result in a low-quality model. Therefore, the three-dimensional structure of $B$. cinerea lipase was determined using thread-based and ab initio approaches. The $B$. cinerea lipase sequence was used for the tertiary structure prediction after removal of the signal peptide. I-TASSER, Phyre2, and the Robetta web server were used to determine the tertiary structure of the lipase. I-TASSER (https:/ / zhanglab.dcmb.med.umich.edu/ I-TASSER/, accessed on 7 June 2021) is a thread-based tool that uses a hierarchy-based approach to predict the protein structure and annotate its structure-based function [58]. Phyre2.0 uses the remote homology detection method to predict the three-dimensional structure of proteins. The Robetta web server (https:/ / robetta.bakerlab.org/, accessed on 9 June, 2021) was used to determine the ab initio and thread-based structure prediction of B. cinerea lipase [59].

\subsection{Protein Model Validation}

All output models were verified by Q-mean, ERRAT, and PROCHECK (https:// saves.mbi.ucla.edu/, accessed on 10 June 2021) [60]. ERRAT analyzes the patterns of nonbonded atomic interaction present in protein, while PROCHECK provides information on the overall structural geometry. The best protein model was refined by the 3Drefine webserver (http:/ / sysbio.rnet.missouri.edu/3Drefine/ accessed on 11 June 2021) [58]. The physicochemical properties of the final protein model were determined using the ExPASy's ProtParam tool (https:/ / web.expasy.org/protparam/ accessed on 12 June 2021) [61].

\subsection{Binding Site Prediction}

The refined protein model was analyzed for binding site prediction using the CASTp webserver (http:/ / sts.bioe.uic.edu/castp/index.html?1bxw, accessed on 13 June 2021) [49]. DoGSiteScorer web server (https:/ / bio.tools/dogsitescorer, accessed on 13 June 2021) was used for the validation of binding sites [48]. Binding site prediction gives information on the active residues involved in the catalytic site for ligand attachment.

\subsection{Ligand Preparation}

Plant lipids were identified from the Plant Fatty Acid database (https: / plantfadb. $\mathrm{org} /$, accessed on 13 June 2021) [62], and three-dimensional structures of 161 plant lipids were downloaded in .sdf format from the PubChem database (https://pubchem.ncbi. nlm.nih.gov/\#query=plant\%20fatty\%20acids, accessed on 15 June 2021) and selected as ligands [63]. Ligands were converted from .sdf format to. pdbqt format using Open Babel at $\mathrm{pH} 7$ [64] to perform molecular docking. 


\subsection{Protein Preparation}

The refined protein structure was prepared and converted into .pdbqt format from .pdb format using the MGL tool (http:/ / mgltools.scripps.edu/downloads, accessed on 19 June 2021) [65]. Water molecules were removed, whereas polar hydrogens were added to the protein.

\subsection{Molecular Docking}

Molecular docking was performed to investigate the appropriate ligands that energetically fit into the protein binding site. AutoDock Vina [65] was used for molecular docking. The top ten compounds having the least number of binding affinities were selected, and a boxplot was generated using R-studio with ggplot2 [66]. The output .pdbqt were combined with the respective protein, and the protein-ligand interactions were determined using Protein-Ligand Interaction Profiler (https:/ / plip-tool.biotec.tu-dresden.de/plipweb / plip/index, accessed on 30 June 2021).

\subsection{Molecular Dynamics Simulation}

A molecular dynamics simulation of $20 \mathrm{~ns}$ was performed to investigate the backbone stability of $B$. cinerea lipase with the top three ligand-protein complexes having the least number of binding affinities. GROMACS 5.1 was used for the molecular dynamics simulations [67]. CHARMM 36-feb2021 forcefield was used for the protein topology preparation by using pdb2gmx. CHARMM General Forcefield CGenFF online server ( https: / / cgenff.umaryland.edu/, accessed on 5 July 2021) was used for the initial ligand topology. Ligand and protein were combined and centralized in the dodecahedron. 2 $\mathrm{Na}^{+}$counterions were added to neutralize the system. The steepest descent minimization algorithm was used to neutralize the energy of the system. To carry out the equilibrium of ions and the solvents, a position-restraining simulation was performed. NVT (constant particles number: N; volume: $\mathrm{V}$; and temperature: T) was executed for 100 ps in a $300 \mathrm{~K}$ temperature bath with a constant coupling of $0.1 \mathrm{ps}$. NPT (constant particles number: N; pressure: $\mathrm{P}$; and temperature: T) was executed at 1 bar constant pressure and the coupling constant of $0.2 \mathrm{ps}$. Final molecular dynamics simulation was performed for $20 \mathrm{~ns}$. The root mean square fluctuations (RMSF), the root mean square deviation (RMSD), and the radius of gyration were calculated between the protein and ligands by using GROMACS.

\section{Conclusions}

The conversion of plant triglycerides into biofuel using $B$. cinerea lipase as a catalyst could be a promising approach for the assimilation of plant-based fatty acids as precursor raw material for environmentally sustainable biofuel or biodiesel production. In the current study, molecular docking and molecular dynamics simulations were performed for identifying the potential of $B$. cinerea lipase as a biofuel-catalyzing agent. The MD simulations results indicate the stable RMSD between the ligand and protein. Hence, it is inferred that B. cinerea lipase is a promising catalyst for plant fatty acid residual bioconversion into biofuel.

Author Contributions: Conceptualization, M.F.B.; Methodology, T.F., Z.Z. and S.F.; Software, R.Z.P., T.F., Z.Z. and S.F.; Validation, T.F., Z.Z. and S.F.; Formal Analysis, T.F., Z.Z., S.F.; Investigation, T.F., Z.Z. and S.F.; Resources, T.F., Z.Z. and S.F.; Data Curation, T.F., Z.Z. and S.F.; Writing-Original Draft Preparation, T.F.; Writing-Review and Editing, M.F.B., F.A., Z., N.V. and R.Z.P.; Supervision, M.F.B. All authors have read and agreed to the published version of the manuscript.

Funding: This research received no external funding.

Data Availability Statement: The data presented in this study are available in the article.

Conflicts of Interest: The authors declare no conflict of interest. 


\section{References}

1. Lee, S.; Posarac, D.; Ellis, N. Process simulation and economic analysis of biodiesel production processes using fresh and waste vegetable oil and supercritical methanol. Chem. Eng. Res. Des. 2011, 89, 2626-2642. [CrossRef]

2. Aguieiras, E.C.; Cavalcanti-Oliveira, E.D.; Freire, D.M. Current status and new developments of biodiesel production using fungal lipases. Fuel 2015, 159, 52-67. [CrossRef]

3. Abbaszaadeh, A.; Ghobadian, B.; Omidkhah, M.R.; Najafi, G. Current biodiesel production technologies: A comparative review. Energy Convers. Manag. 2012, 63, 138-148. [CrossRef]

4. Department of State Development, Manufacturing, Infrastructure and Planning. Queensland Hydrogen Industry Strategy 2019-2024; Department of State Development, Manufacturing, Infrastructure and Planning: Queensland, Australia, 2019.

5. Malani, R.S.; Moholkar, V.S.; Elbashir, N.O.; Choudhury, H.A. Chapter 2: Advancements of Cavitation Technology in Biodiesel Production-from Fundamental Concept to Commercial Scale-Up. In Liquid Biofuels: Fundamentals, Characterization, and Applications; Scrivener Publishing LLC: Beverly, MA, USA, 2021; pp. 39-76.

6. Fleuri, L.F.; de Oliveira, M.C.; Arcuri, M.d.L.C.; Capoville, B.L.; Pereira, M.S.; Delgado, C.H.O.; Novelli, P.K. Production of fungal lipases using wheat bran and soybean bran and incorporation of sugarcane bagasse as a co-substrate in solid-state fermentation. Food Sci. Biotechnol. 2014, 23, 1199-1205. [CrossRef]

7. Durrett, T.P.; Benning, C.; Ohlrogge, J. Plant triacylglycerols as feedstocks for the production of biofuels. Plant J. 2008, 54, 593-607. [CrossRef]

8. No, S.-Y. Inedible vegetable oils and their derivatives for alternative diesel fuels in CI engines: A review. Renew. Sustain. Energy Rev. 2011, 15, 131-149. [CrossRef]

9. Zabed, H.M.; Akter, S.; Yun, J.; Zhang, G.; Awad, F.N.; Qi, X.; Sahu, J.N. Recent advances in biological pretreatment of microalgae and lignocellulosic biomass for biofuel production. Sustain. Energy Rev. 2019, 105, 105-128. [CrossRef]

10. Raghavendra, M.; Nayaka, S.C.; Gupta, V.K. Microbial Enzymes for Conversion of Biomass to Bioenergy; Springer: Berlin/Heidelberg, Germany, 2016; pp. 1-26.

11. Li, P.; Makino, H. Liquefied dimethyl ether: An energy-saving, green extraction solvent. In Alternative Solvents for Natural Products Extraction; Springer: Berlin/Heidelberg, Germany, 2014; pp. 91-106.

12. Juangsa, F.B.; Prananto, L.A.; Mufrodi, Z.; Budiman, A.; Oda, T.; Aziz, M. Highly energy-efficient combination of dehydrogenation of methylcyclohexane and hydrogen-based power generation. Appl. Energy 2018, 226, 31-38. [CrossRef]

13. Yang, X.; Zhang, Y.; Pang, H.; Yuan, S.; Wang, X.; Hu, Z.; Zhou, Q.; He, Y.; Yan, Y.; Xu, L. Codisplay of Rhizopus oryzae and Candida rugosa Lipases for Biodiesel Production. Catalysts 2021, 11, 421. [CrossRef]

14. Hama, S.; Tamalampudi, S.; Fukumizu, T.; Miura, K.; Yamaji, H.; Kondo, A.; Fukuda, H. Lipase localization in Rhizopus oryzae cells immobilized within biomass support particles for use as whole-cell biocatalysts in biodiesel-fuel production. J. Biosci. Bioeng. 2006, 101, 328-333. [CrossRef]

15. Weber, N.; Weitkamp, P.; Mukherjee, K.D. Steryl and stanyl esters of fatty acids by solvent-free esterification and transesterification in vacuo using lipases from Rhizomucor miehei, Candida antarctica, and Carica papaya. J. Agric. Food Chem. 2001, 49, 5210-5216. [CrossRef] [PubMed]

16. Morinaga, N.; Maeda, A.; Mizuno, T.; Bunya, M.; Sugihara, S.; Sugihara, A. Synthesis of fatty acid sterol esters using cholesterol esterase from Trichoderma sp. AS59. Enzym. Microb. Technol. 2011, 48, 498-504. [CrossRef]

17. Singh, A.K.; Mukhopadhyay, M. Overview of fungal lipase: A review. Appl. Biochem. Biotechnol. 2012, 166, 486-520. [CrossRef]

18. Gupta, R.; Kumari, A.; Syal, P.; Singh, Y. Molecular and functional diversity of yeast and fungal lipases: Their role in biotechnology and cellular physiology. Prog. Lipid Res. 2015, 57, 40-54. [CrossRef] [PubMed]

19. Fischer, M.; Pleiss, J. The Lipase Engineering Database: A navigation and analysis tool for protein families. Nucleic Acids Res. 2003, 31, 319-321. [CrossRef] [PubMed]

20. Borrelli, G.M.; Trono, D. Recombinant lipases and phospholipases and their use as biocatalysts for industrial applications. Int. J. Mol. Sci. 2015, 16, 20774-20840. [CrossRef]

21. Fjerbaek, L.; Christensen, K.V.; Norddahl, B. A review of the current state of biodiesel production using enzymatic transesterification. Biotechnol. Bioeng. 2009, 102, 1298-1315. [CrossRef] [PubMed]

22. Castillo, L.; Plaza, V.; Larrondo, L.F.; Canessa, P.; Science, P. Recent advances in the study of the plant pathogenic fungus Botrytis cinerea and its interaction with the environment. Curr. Protein Pept. Sci. 2017, 18, 976-989. [CrossRef]

23. Reis, H.; Pfiffi, S.; Hahn, M. Molecular and functional characterization of a secreted lipase from Botrytis cinerea. Mol. Plant Pathol. 2005, 6, 257-267. [CrossRef]

24. Williamson, B.; Tudzynski, B.; Tudzynski, P.; Van Kan, J.A.L. Botrytis cinerea: The cause of grey mould disease. Mol. Plant Pathol. 2007, 8, 561-580. [CrossRef] [PubMed]

25. Guarnieri, G.d.P.; Almeida, S.T.d.; Paula, A.S.; Medeiros, V.L.; Vasconcellos, A.d.; Nery, J.G.; Aranda, D.A. Potential new biocatalysts for biofuel production: The fungal lipases of Thermomyces lanuginosus and Rhizomucor miehei immobilized on nanozeolitic supports ion exchanged with lanthanide cations. In Proceedings of the 18. Brazil MRS Meeting, Balneário Camboriú, Brazil, 21-26 September 2019.

26. Du, W.; Li, W.; Sun, T.; Chen, X.; Liu, D. Biotechnology. Perspectives for biotechnological production of biodiesel and impacts. Appl. Microbiol. Biotechnol. 2008, 79, 331-337. [CrossRef] [PubMed] 
27. Demirbas, A.; Bafail, A.; Ahmad, W.; Sheikh, M. Exploitation. Biodiesel production from non-edible plant oils. Energy Explor. Exploit. 2016, 34, 290-318. [CrossRef]

28. Singh, S.; Singh, D. Biodiesel production through the use of different sources and characterization of oils and their esters as the substitute of diesel: A review. Renew. Sustain. Energy Rev. 2010, 14, 200-216. [CrossRef]

29. Brännström, H.; Kumar, H.; Alén, R. Current and potential biofuel production from plant oils. BioEnergy Res. 2018, 11, 592-613. [CrossRef]

30. Juhl, P.B.; Trodler, P.; Tyagi, S.; Pleiss, J. Modelling substrate specificity and enantioselectivity for lipases and esterases by substrate-imprinted docking. BMC Struct. Biol. 2009, 9, 39. [CrossRef] [PubMed]

31. Calero-Rueda, O.; Plou, F.J.; Ballesteros, A.; Martinez, A.T.; Martinez, M.J. Production, isolation and characterization of a sterol esterase from Ophiostoma piceae. Biochim. Biophys. Acta (BBA)_Proteins Proteom. 2002, 1599, 28-35. [CrossRef]

32. Barriuso, J.; Vaquero, M.E.; Prieto, A.; Martínez, M.J. Structural traits and catalytic versatility of the lipases from the Candida rugosa-like family: A review. Biotechnol. Adv. 2016, 34, 874-885. [CrossRef]

33. Kontkanen, H.; Tenkanen, M.; Reinikainen, T. Purification and characterisation of a novel steryl esterase from Melanocarpus albomyces. Enzym. Microb. Technol. 2006, 39, 265-273. [CrossRef]

34. Moya-Salazar, J.; Vértiz-Osores, J.; Jibaja, S.; Acevedo-Espindola, C.; Rupa, R.; Alarcón-Díaz, M. Fungi lipases homology modeling and molecular docking with fatty acids and tripalmitin of palm oil effluent. Arch. Org. Inorg. Chem. Sci. 2019, 4, 493-500.

35. Messaoudi, A.; Belguith, H.; Hamida, J. Three-dimensional structure of Arabidopsis thaliana lipase predicted by homology modeling method. Evol. Bioinform. 2011, 7, EBO.S7122. [CrossRef]

36. Patel, G.B.; Rakholiya, P.; Shindhal, T.; Varjani, S.; Tabhani, N.; Shah, K.R. Lipolytic Nocardiopsis for Reduction of Pollution Load in Textile Industry Effluent and SWISS Model for Structural Study of Lipase. Bioresour. Technol. 2021, 341, 125673. [CrossRef] [PubMed]

37. Sehgal, S.A.; Mirza, A.H.; Tahir, R.A.; Mir, A. Quick Guideline for Computational Drug Design; Bentham Science Publishers: Sharjah, United Arab Emirates, 2018.

38. Tahir, H.M.; Abd Rahman, R.N.Z.R.; Leow, A.T.C.; Ali, M.S.M. Expression, characterisation and homology modelling of a novel hormone-sensitive lipase (HSL)-like esterase from Glaciozyma antarctica. In Novel Enzyme and Whole-Cell Biocatalysts; MDPI: Basel, Switzerland, 2020; p. 85.

39. Hermoso, J.A.; Sanz-Aparicio, J.; Molina, R.; Juge, N.; Gonzalez, R.; Faulds, C.B. The crystal structure of feruloyl esterase A from Aspergillus niger suggests evolutive functional convergence in feruloyl esterase family. J. Mol. Biol. 2004, 338, 495-506. [CrossRef]

40. Bahaman, A.H.; Wahab, R.A.; Abdul Hamid, A.A.; Abd Halim, K.B.; Kaya, Y. Molecular docking and molecular dynamics simulations studies on $\beta$-glucosidase and xylanase Trichoderma asperellum to predict degradation order of cellulosic components in oil palm leaves for nanocellulose preparation. J. Biomol. Struct. Dyn. 2021, 39, 2628-2641. [CrossRef]

41. Ezeilo, U.R.; Lee, C.T.; Huyop, F.; Zakaria, I.I.; Wahab, R.A. Raw oil palm frond leaves as cost-effective substrate for cellulase and xylanase productions by Trichoderma asperellum UC1 under solid-state fermentation. J. Environ. Manag. 2019, 243, 206-217. [CrossRef] [PubMed]

42. Dutta, S.; Lanvin, B.; Wunsch-Vincent, S. Global Innovation Index 2018: Energizing the World with Innovation; WIPO: Geneva, Switzerland, 2018.

43. Curto, V.; Einav, L.; Finkelstein, A.; Levin, J.; Bhattacharya, J. Health care spending and utilization in public and private Medicare. Am. Econ. J. Appl. Econ. 2019, 11, 302-332. [CrossRef] [PubMed]

44. Xing, S.; Zhu, R.; Li, C.; He, L.; Zeng, X.; Zhang, Q. technology. Gene cloning, expression, purification and characterization of a sn-1, 3 extracellular lipase from Aspergillus niger GZUF36. J. Food Sci. Technol. 2020, 57, 2669-2680. [CrossRef]

45. Brandao, L.M.d.S.; Barbosa, M.S.; Souza, R.L.; Pereira, M.M.; Lima, A.S.; Soares, C.M.F. Lipase activation by molecular bioimprinting: The role of interactions between fatty acids and enzyme active site. Biotechnol. Prog. 2021, 37, e3064. [CrossRef] [PubMed]

46. Almeida, L.C.; Barbosa, M.S.; de Jesus, F.A.; Santos, R.M.; Fricks, A.T.; Freitas, L.S.; Pereira, M.M.; Lima, Á.S.; Soares, C.M.F. Enzymatic transesterification of coconut oil by using immobilized lipase on biochar: An experimental and molecular docking study. Biotechnol. Appl. Biochem. 2020, 68, 801-808. [CrossRef] [PubMed]

47. Jin, F.-J.; Katayama, T.; Maruyama, J.-I.; Kitamoto, K. Comparative genomic analysis identified a mutation related to enhanced heterologous protein production in the filamentous fungus Aspergillus oryzae. Appl. Microbiol. Biotechnol. 2016, 100,9163-9174. [CrossRef]

48. Volkamer, A.; Kuhn, D.; Rippmann, F.; Rarey, M. DoGSiteScorer: A web server for automatic binding site prediction, analysis and druggability assessment. Bioinformatics 2012, 28, 2074-2075. [CrossRef] [PubMed]

49. Tian, W.; Chen, C.; Lei, X.; Zhao, J.; Liang, J. CASTp 3.0: Computed atlas of surface topography of proteins. Nucleic Acids Res. 2018, 46, W363. [CrossRef]

50. Hæffner, F.; Norin, T.; Hult, K. Molecular modeling of the enantioselectivity in lipase-catalyzed transesterification reactions. Biophys. J. 1998, 74, 1251-1262. [CrossRef]

51. Khan, M.; Kumar, A. Computational modelling and protein-ligand interaction studies of SMlipA lipase cloned from forest metagenome. J. Mol. Graph. Model. 2016, 70, 212-225. [CrossRef] [PubMed] 
52. Yang, X.; Jiang, L.; Jia, Y.; Hu, Y.; Xu, Q.; Xu, X.; Huang, H. Counteraction of trehalose on N, N-dimethylformamide-induced Candida rugosa lipase denaturation: Spectroscopic insight and molecular dynamic simulation. PLoS ONE 2016, 11, e0152275. [CrossRef] [PubMed]

53. Wedberg, R.; Abildskov, J.; Peters, G.H. Protein dynamics in organic media at varying water activity studied by molecular dynamics simulation. J. Phys. Chem. B 2012, 116, 2575-2585. [CrossRef]

54. Thompson, J.D.; Gibson, T.J.; Higgins, D. Multiple sequence alignment using ClustalW and ClustalX. Curr. Protoc. Bioinform. 2003, 2. [CrossRef]

55. Reynolds, S.M.; Käll, L.; Riffle, M.E.; Bilmes, J.A.; Noble, W.S. Transmembrane topology and signal peptide prediction using dynamic bayesian networks. PLoS Comput. Biol. 2008, 4, e1000213. [CrossRef] [PubMed]

56. Armenteros, J.J.A.; Tsirigos, K.D.; Sønderby, C.K.; Petersen, T.N.; Winther, O.; Brunak, S.; von Heijne, G.; Nielsen, H. SignalP 5.0 improves signal peptide predictions using deep neural networks. Nat. Biotechnol. 2019, 37, 420-423. [CrossRef] [PubMed]

57. Buchan, D.W.; Minneci, F.; Nugent, T.C.; Bryson, K.; Jones, D.T. Scalable web services for the PSIPRED Protein Analysis Workbench. Nucleic Acids Res. 2013, 41, W349-W357. [CrossRef]

58. Zhang, Y. I-TASSER server for protein 3D structure prediction. BMC Bioinform. 2008, 9, 40. [CrossRef]

59. Kim, D.E.; Chivian, D.; Baker, D. Protein structure prediction and analysis using the Robetta server. Nucleic Acids Res. 2004, 32, W526-W531. [CrossRef] [PubMed]

60. Colovos, C.; Yeates, T.O. Verification of protein structures: Patterns of nonbonded atomic interactions. Protein Sci. 1993, 2, 1511-1519. [CrossRef]

61. Gasteiger, E.; Hoogland, C.; Gattiker, A.; Wilkins, M.R.; Appel, R.D.; Bairoch, A. Protein identification and analysis tools on the ExPASy server. In The Proteomics Protocols Handbook; Springer: Berlin/Heidelberg, Germany, 2005; pp. 571-607.

62. Ohlrogge, J.; Thrower, N.; Mhaske, V.; Stymne, S.; Baxter, M.; Yang, W.; Liu, J.; Shaw, K.; Shorrosh, B.; Zhang, M.; et al. Plant FA $\mathrm{db}$ : A resource for exploring hundreds of plant fatty acid structures synthesized by thousands of plants and their phylogenetic relationships. Plant J. 2018, 96, 1299-1308. [CrossRef] [PubMed]

63. Kim, S.; Thiessen, P.A.; Bolton, E.E.; Chen, J.; Fu, G.; Gindulyte, A.; Han, L.; He, J.; He, S.; Shoemaker, B.A.; et al. PubChem substance and compound databases. Nucleic Acids Res. 2016, 44, D1202-D1213. [CrossRef]

64. Release, S.J. LigPrep; Schrödinger, LLC: New York, NY, USA, 2017.

65. Trott, O.; Olson, A.J. AutoDock Vina: Improving the speed and accuracy of docking with a new scoring function, efficient optimization, and multithreading. J. Comput. Chem. 2010, 31, 455-461. [CrossRef] [PubMed]

66. Wickham, H. ggplot2. Wiley Interdiscip. Rev. Comput. Stat. 2011, 3, 180-185. [CrossRef]

67. Van Der Spoel, D.; Lindahl, E.; Hess, B.; Groenhof, G.; Mark, A.E.; Berendsen, H.J. GROMACS: Fast, flexible, and free. J. Comput. Chem. 2005, 26, 1701-1718. [CrossRef] [PubMed] 